\title{
Non-destructive testing of metallic materials using passive and active infrared thermography
}

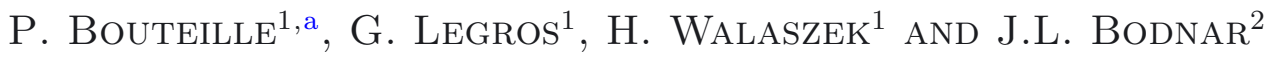 \\ 1 CETIM, 52, avenue Félix Louat, 60300 Senlis, France \\ 2 GRESPI, UFR Sciences Exactes et Naturelles, BP 1039, 51687 Reims Cedex 2, France
}

Received 7 January 2014, Accepted 15 May 2014

\begin{abstract}
In this work, we approach the possibilities of infrared thermography for non-destructive testing of metallic materials. We show that the passive alternative of the method makes it possible to improve detection of surface defects existing in deep-drawn parts and visible to the naked eye. We then show that active infrared thermography, in particular coupled with induction excitation, can replace in certain cases the magnetic particle inspection, allowing the detection of very fine defects in forged parts. Finally, the study of a stepped block confirms the possibilities of active infrared thermography to detect defects not open to the surface and underlying defects.
\end{abstract}

Key words: Non destructive testing / infrared thermography / defect detection / metallic samples / industrial samples

\section{Introduction}

The ever stricter requirements issued by customers often result in the need to carry out a quality inspection on $100 \%$ of the parts produced, thus requiring industrialists to implement increasingly sophisticated non-destructive testing strategies. In order to help industrialists to take up this challenge, CETIM is performing a continuous technological watch on non-destructive testing techniques under development and contributes to transfer the most promising techniques to the companies of the mechanical industry. Infrared thermography is one of those techniques and today it has become the reference method in many applications such as safety, inspection of electrical installations or inspection of the thermal insulation of buildings. Infrared thermography has some advantages: it is an overall method and it has a significant potential for automation. It has already been used successfully for a few years now for nondestructive testing of materials with rather slow thermal kinetics (composites, building construction materials, works of art, plastics, etc.). With the technical developments in faster testing equipment and data processing tools, it is now possible to contemplate the application of this technique to non-destructive testing of materials with faster thermal kinetics, such as metallic materials.
This is the purpose of this study. Non-destructive testing of materials can be either passive or active. In the first case, the method consists in analysing the radiation response given spontaneously by the analysed sample. This variant is more often used to detect surface defects such as rather large cracks open to the surface. In the second case (more suitable for the detection of smaller defects or defects not open to the surface), the method consists in applying an external excitation to the tested item and analysing the photothermal response given by the sample. This method is generally used to detect delamination in composite materials or separation of plated coatings in works of art. In the study presented here, we will detail the possibilities of both infrared thermography variants for non-destructive testing of metallic materials commonly used in the mechanical industry. Our presentation is broken down into three parts. First, we will present the principle of non-destructive testing of materials using infrared thermography. Then we will detail the possibilities of passive infrared thermography to detect surface defects in deep-drawn parts. Finally, we will review the possibilities of active infrared thermography for the detection of small defects in forged parts, in comparison with magnetic particle testing, and for the detection of defects in a stepped block.

\footnotetext{
${ }^{a}$ Corresponding author: patrick.bouteille@cetim.fr
} 


\section{Non-destructive testing by infrared thermography}

Infrared thermography is a non-destructive testing method widely used in the industrial world, for instance for thermal diagnosis of buildings, for safety or for the inspection of electrical cabinets [1]. The passive variant of infrared thermography consists in acquiring, using a thermal camera, the radiation flux naturally emitted by the examined body [2]. The image obtained, called "thermogram", can therefore reveal an abnormal variation of the radiation flux and evidence a defect. This variation may depend on two physical phenomena: an optical phenomenon and a thermal phenomenon. In the first case, the presence of a defect can generate a change in the radiation properties of the surface of the analysed sample, thereby allowing the detection of the defect. This happens with cracks open to the surface, for instance. In that particular case, the radiation behaviour of the crack can be compared to that of a micro black body. It generates an apparent emissivity value which can become much higher than that of the surface of the analysed sample; this can then generate a radiation flux peak just above the defect, thereby allowing its detection [3]. In the second case (thermal phenomenon), the presence of a defect can generate some asymmetry in the spatial distribution of temperature, which also leads to detection. This spatial disturbance of the radiation flux is widely used in medical applications of infrared thermography. If the parts to be tested do not spontaneously give information as to their preservation state, it becomes necessary to disturb the tested sample and analyse its thermal response so as to collect this information. This is therefore active infrared thermography [3]. Several disturbance modes can then be used: the analysed material can be excited optically (flash lamps, halogen lamps, laser, etc.), electromagnetically (eddy currents), mechanically (ultrasounds) or by a hot air flow [4-11]. The selected method, the position of the source and the heating time are dependent on the material to be tested, its thickness and the nature, position and orientation of the expected defect. Furthermore, various excitation methods can be implemented: let us mention flash lamp excitation, step heating excitation or harmonic excitation. In order to study fragile materials, such as biological materials or works of art, random excitations can also be used [12]. Finally, for the selection of the experimental conditions, it is also important to define the position of the camera and of the excitation source with respect to the tested part: camera and source on the same side of the part (reflection) or on both sides of the part (transmission) and angle to be provided between these different items to prevent spurious reflections [13-20]. All these different possibilities lead to many ways of implementing the active infrared thermography method and each way will answer a particular problem. In this work, we have implemented three variants of active infrared thermography: active infrared thermography with flash lamp optical excitation, infrared thermography associated with laser excitation, and infrared thermography associated with eddy current excitation (induction).

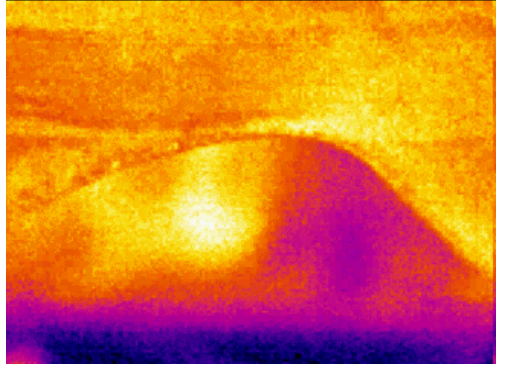

Fig. 1. Thermogram obtained during the study of a sound car suspension part.

\section{Applications of passive infrared thermography for the inspection of deep-drawn parts}

Deep-drawn parts can have various types of defects, among which we may mention cracks or incipient cracks. These defects result from excessive elongation of the material, and they are likely to adversely affect the mechanical characteristics of the part and, therefore, they can embrittle it during its use. During production, chips may also migrate in the tool and end up between the tool and the material to be formed; the surface of the part then has a mark. Customers usually do not accept these "cosmetic" defects. As a result, industrialists in this sector are looking for an on-line inspection method which would be able to detect such defects. Since infrared thermography has a significant potential for automation, we found it interesting to take a look at its possibilities for the inspection of deep-drawn parts. For this study, we examined three types of conventional industrial defects: cracks in car suspension parts, incipient cracks and fissures in car crankcases and, finally, appearance defects in car mounting plates caused by chips which migrated. Now let us examine the results obtained in this scope.

\subsection{Detection of cracks in car suspension parts}

The first study developed in passive infrared thermography concerns the detection of cracks in car suspension parts. These parts are $3 \mathrm{~mm}$ thick approximately, and cracks can appear during the parts forming process. We analysed sound and defective parts. The results obtained are presented in Figure 1 for the sound part and in Figure 2 for the defective part. They clearly show that a crack gives a higher radiation signal at the exact location of the defect, thereby allowing detection.

\subsection{Detection of incipient cracks and fissures in car engine crankcases}

The second study developed in passive infrared thermography concerns the detection of incipient cracks and fissures in car engine crankcases. For that purpose, we studied three coated steel crankcases. The first one is a 


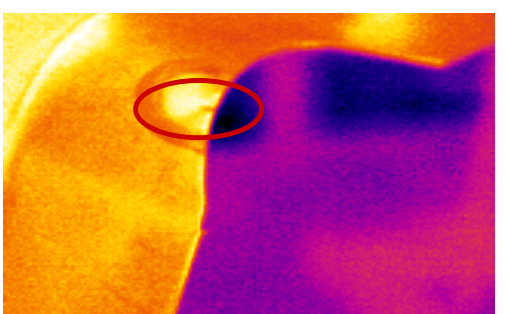

Fig. 2. Thermogram obtained during the study of a defective car suspension part.

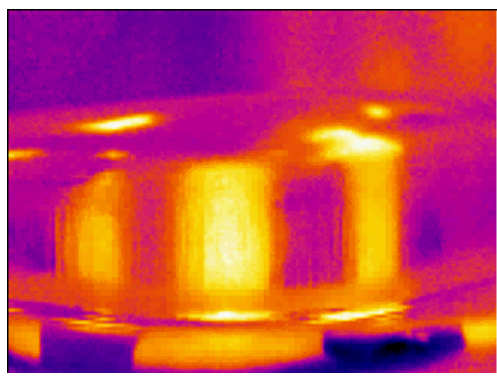

Fig. 3. Thermogram obtained during the examination of a sound crankcase.

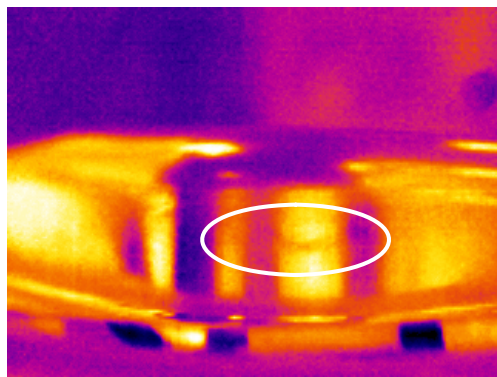

Fig. 4. Thermogram obtained during the examination of a crankcase with an incipient crack.

sound crankcase, the second one has an incipient crack and the last one has a through crack. As the previous result showed the feasibility of the method, we wanted in this new study to approach the experimental conditions encountered at the outlet of a deep-drawing press. For that purpose, we covered the crankcases with a film of grease to simulate the drawing lubricant. The results obtained are presented in Figures 3 to 5 . Figure 3 corresponds to the thermogram obtained during the examination of the sound crankcase. Figure 4 corresponds to the thermogram obtained during the examination of the incipient crack; it shows a peculiar radiation signature at the location of the crack. This shows the possibilities of passive infrared thermography to detect this type of defects in conditions close to those found in a factory. Figure 5 corresponds to the thermogram obtained during the examination of the cracked crankcase. Here again, a higher radiation signal is visible at the location of the defect, thereby allowing its detection. Finally, the comparison between Figures 4 and 5, shows that the radiation signature of the defect is higher for a deeper defect.

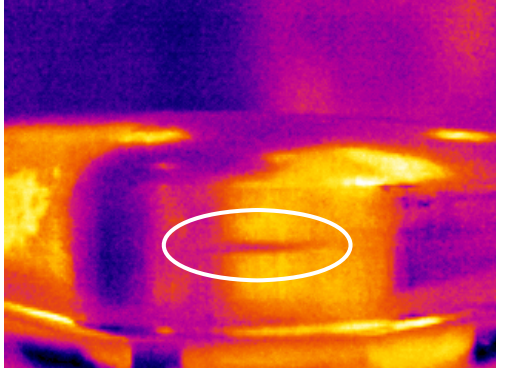

Fig. 5. Thermogram obtained during the examination of a crankcase with a through crack.

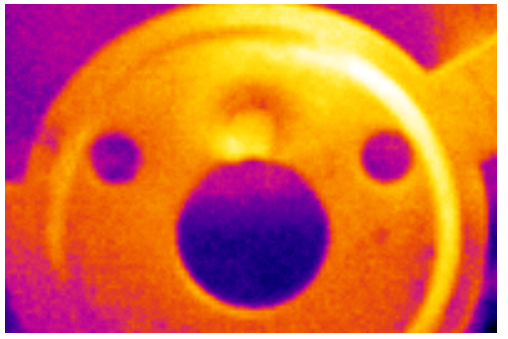

Fig. 6. Thermogram obtained during the examination of a car mounting plate exhibiting an appearance defect caused by a migrating chip (chip side).

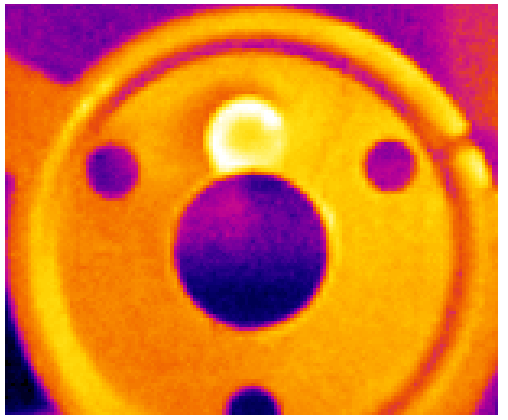

Fig. 7. Thermogram obtained during the examination of a car mounting plate exhibiting an appearance defect caused by a migrating chip (face opposite to the chip).

This observation is interesting since it can pave the way for dimensional characterisation of this type of defects.

\subsection{Detection of appearance defects in car mounting plates caused by migrating chips}

The third study developed in passive infrared thermography concerns the detection of migrating waste in car mounting plates made of steel. This is an appearance defect of industrial parts, caused by chips which migrated in the tooling. As in the previous cases, Figures 6 and 7 show the possibility of detection of this defect, as it changes the surface radiation properties of the part.

The interest of this third study, after laboratory experiments, was the possibility to test the passive method at the end of a production line. This study on an industrial site was developed in normal production conditions. 


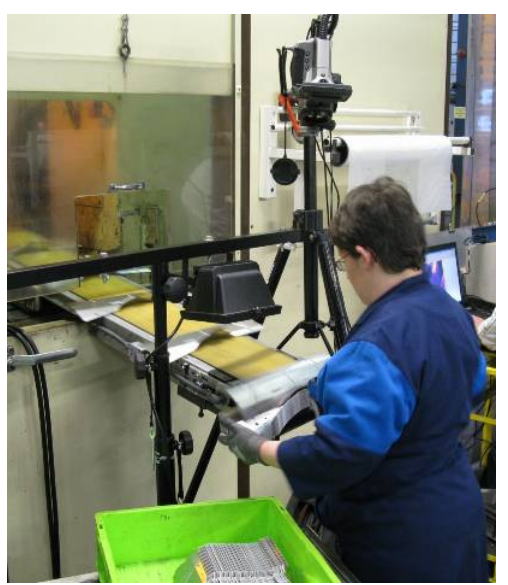

Fig. 8. Experimental device selected for the study.

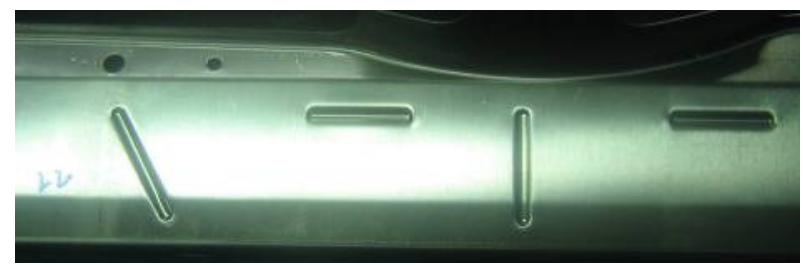

Fig. 9. Sound part.

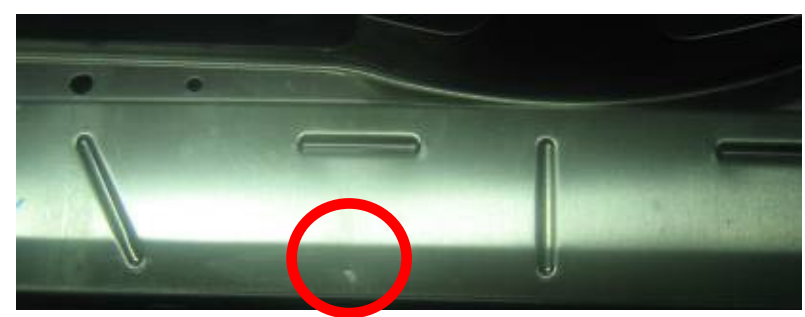

Fig. 10. Part exhibiting an appearance defect caused by a migrating chip.

The parts were analysed as they travelled in the production line; therefore, they were warm and covered in lubricant. The infrared camera was installed at press outlet. It continuously shot the parts to be inspected (Fig. 8).

During this measurement campaign, approximately one hundred parts were inspected, among which approximately ten defective parts. As in the previous case, these defective parts were characterised by an appearance defect (Figs. 9 and 10).

The results obtained during this on-site study are presented in Figures 11 and 12. Figure 11 corresponds to the typical result obtained during the analysis of a sound part. Figure 12 corresponds to an example of result obtained during the analysis of a defective part. These figures clearly show that, even in an industrial situation, the presence of a defect generates a radiation signature which can be detected using passive infrared thermography. This result is very interesting since it can pave the way for real time, on-site detection of appearance defects.

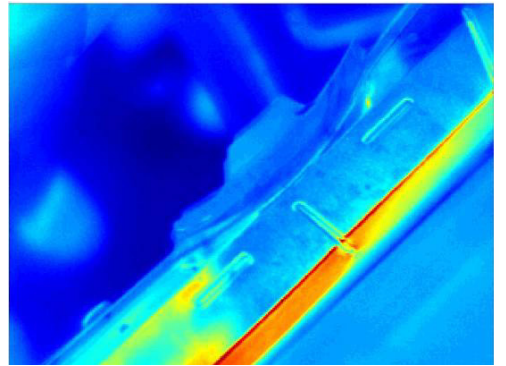

Fig. 11. Thermogram obtained during the study of a sound part.

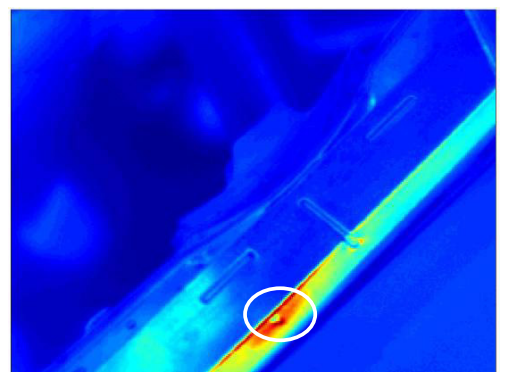

Fig. 12. Thermogram obtained during the study of a part exhibiting an appearance defect caused by chip migration.

\section{Applications of active infrared thermography for the inspection of metallic materials}

After this approach of the possibilities of passive infrared thermography for nondestructive testing of metallic materials, we started to study the possibilities of the active variant of the method. As a matter of fact, in the case of fine defects or defects not open to the surface, the passive method rapidly becomes unsuitable. In such conditions, the signature of the defect searched for is either lost in noise or it does not exist. Therefore, in order to allow these samples to be studied, we implemented the active variant of infrared thermography on forged parts. This type of parts is usually inspected visually or subjected to magnetic particle testing. Visual inspection does not allow thin defects to be detected, and its efficiency is limited when operators' concentration is decreasing. Magnetic particle testing is a reliable and robust method, but it requires chemicals and uses high electromagnetic fields. Consequently, it is a source of pollution and furthermore it has effects on the operators and the environment. Therefore, it appears interesting to test more environmentally friendly methods such as active infrared thermography.

\subsection{Study of forged parts}

\subsubsection{Detection of forging laps in a gear}

The first sample we studied using active infrared thermography was a cracked transmission gear (Fig. 13). 


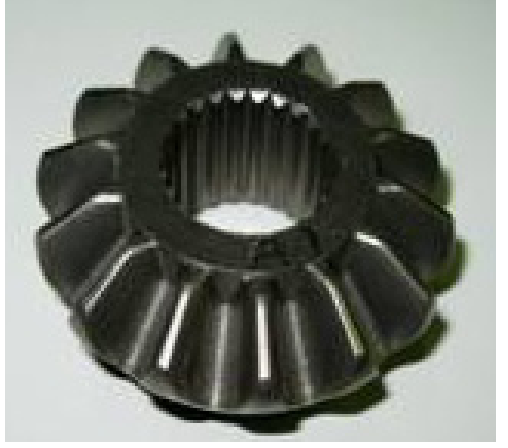

Fig. 13. Analysed transmission gear.

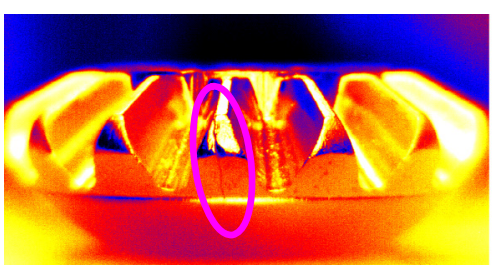

Fig. 14. Thermogram obtained with passive infrared thermography.

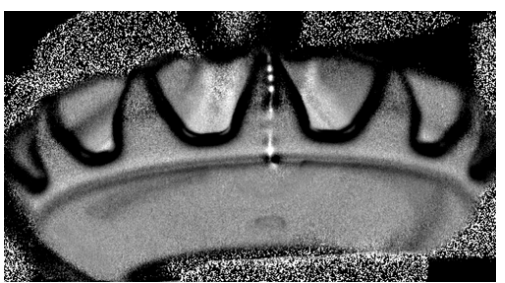

Fig. 15. Thermogram obtained with active infrared thermography.

Following our previous studies, we first analysed this sample using passive infrared thermography. The thermogram obtained shows many reflection areas, and the defect cannot be clearly identified (Fig. 14).

Then we analysed the gear using active infrared thermography, with induction excitation. The result obtained is presented after processing of the picture sequence. This processing is a frequency analysis of the temporal evolution of temperatures. Based on the series of recorded thermal images, we calculated a Fourier transform of this evolution, for each pixel. As this transform is a complex series which depends on the frequency, it is possible to obtain images which show the phase and the amplitude. In our case, Figure 15 shows a phase image. The defect is more clearly visible than with the passive analysis, which therefore confirms the interest of active thermography.

\subsubsection{Detection of forging laps in a hub}

The objective of the next study was to assess the possibilities of the infrared method to detect very small forging laps located in a hub (Fig. 16).

The magnetic particle inspection shows that the studied hub has two cracks which are not visible with the

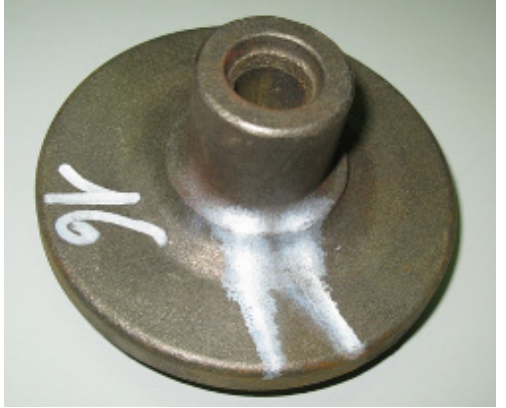

Fig. 16. Analysed forged hub.

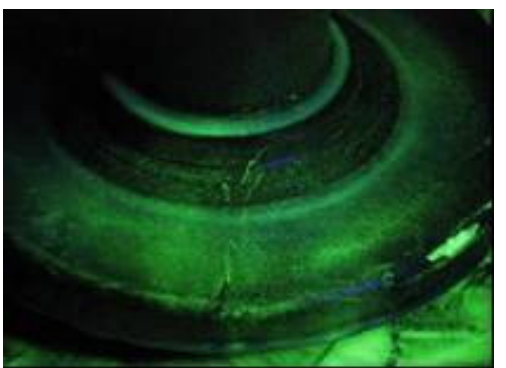

Fig. 17. Magnetic particle inspection of the hub (flat face).

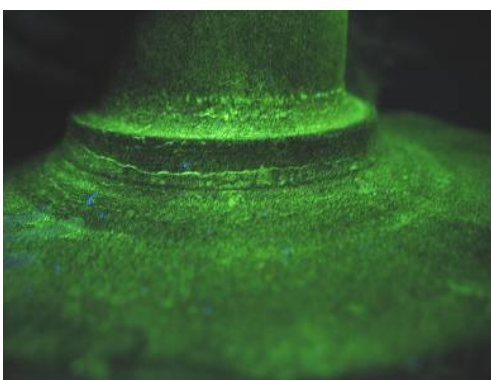

Fig. 18. Magnetic particle inspection of the hub (fillet radius).

naked eye. The first crack extends from the flat face of the part to the fillet radius (Fig. 17). The second crack is located in the fillet radius (Fig. 18).

Then we analysed this sample using active infrared thermography and with three different excitation modes: laser, flash lamp and induction. The results obtained are presented in Figures 19 to 23. Figure 19 corresponds to laser excitation, it shows an indication in the fillet radius of the hub. However, this excitation source, which allows good defect detection, is not compatible with the inspection rates on this type of industrial parts. Figures 20 and 21 correspond to the inspection of the hub after optical excitation using a $3.5 \mathrm{~kJ}$ flash lamp; they show higher photothermal signals at the location of the defects, thereby allowing detection. In this case, the inspection is much faster but it is susceptible to the variations of emissivity of the part to be inspected. Finally, the last tested excitation was induction. The principle is based on generating eddy currents in the part to be inspected by sending a high alternating current in a coil located in the vicinity of the part. These currents will heat the part through Joule effect. Figures 22 and 23 show the most contrasted 


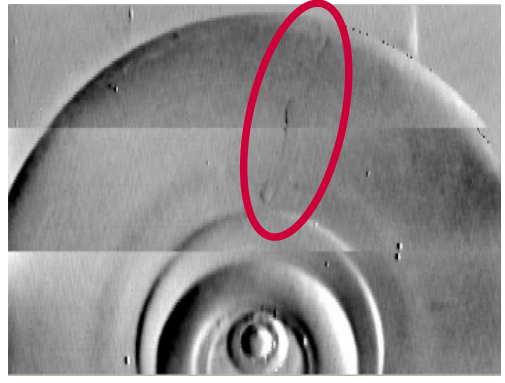

Fig. 19. Thermogram obtained during the examination of the hub (laser excitation).

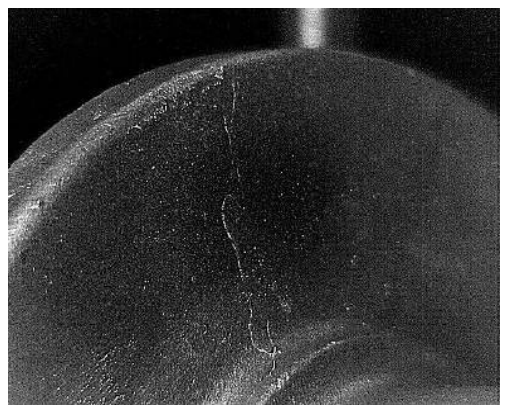

Fig. 20. Thermogram obtained during the examination of the flat face of the forged hub (flash lamp excitation).

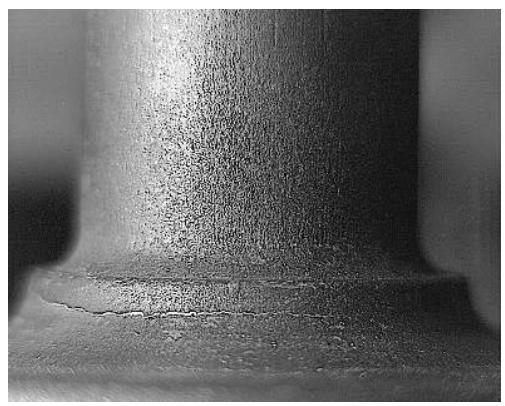

Fig. 21. Thermogram obtained during the examination of the fillet radius of the forged hub (flash lamp excitation).

signatures of the methods implemented in this study. Furthermore, the implementation of induction excitation is compatible with the industrial constraints encountered in a forging plant. This study demonstrates that induction thermography is very interesting to detect micro-cracks.

\subsubsection{Detection of cracks in a forged ball joint}

Further to this very positive study, we continued our investigations on a forged ball joint (Fig. 24).

The conventional magnetic particle inspection revealed the presence of a crack over the entire length of the ball joint (Fig. 25).

The result obtained with induction excitation thermography is presented on Figure 26. It shows a white line which corresponds to the photothermal signature of the crack, further to a 140-ms acquisition which included $70 \mathrm{~ms}$ of induction excitation and $70 \mathrm{~ms}$ of cooling.

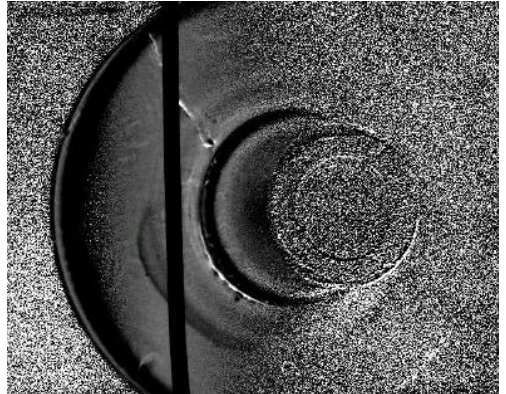

Fig. 22. Thermogram obtained during the examination of the flat face of the forged hub (induction excitation).

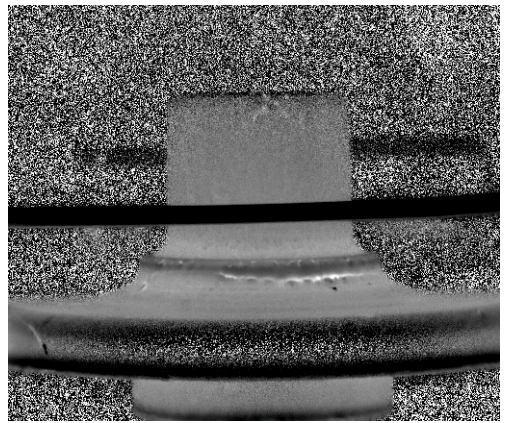

Fig. 23. Thermogram obtained during the examination of the fillet radius of the forged hub (induction excitation).

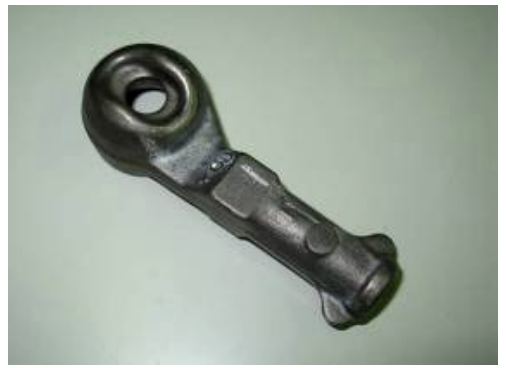

Fig. 24. Analysed forged ball joint.

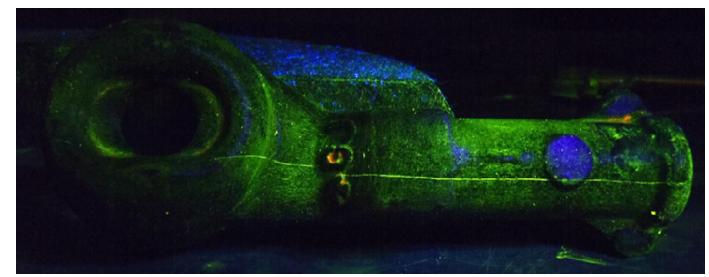

Fig. 25. Magnetic particle inspection of the forged ball joint.

The quality of the detection and the short time necessary for the test confirm the interest of induction thermography to inspect forged parts.

\subsubsection{Detection of cracks in a threaded rod}

Finally, the last industrial sample for which we present results is a threaded rod. The magnetic particle inspection revealed a longitudinal crack in the part (Fig. 27). 


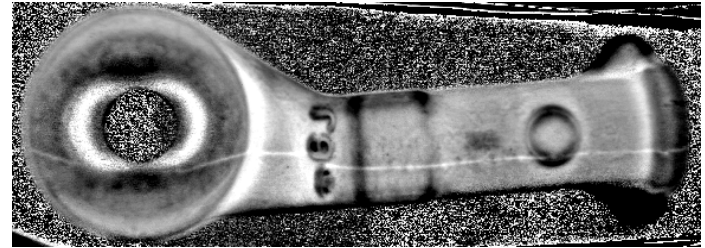

Fig. 26. Thermogram obtained during the active infrared thermography analysis of the forged ball joint.

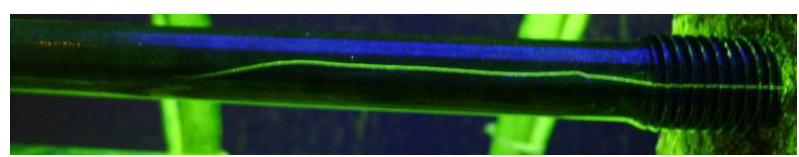

Fig. 27. Magnetic particle inspection of a threaded rod.

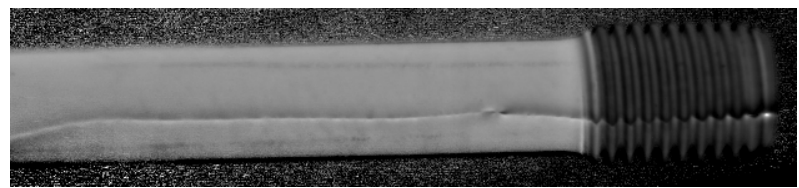

Fig. 28. Thermogram obtained during the active infrared thermography inspection of a threaded rod.

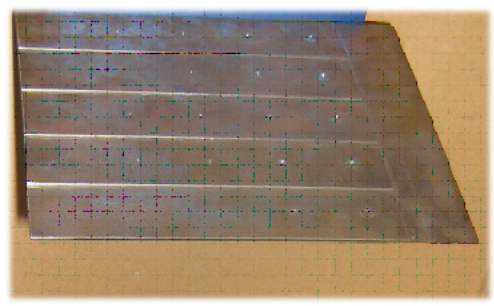

Fig. 29. Examined stepped block.

As previously, this sample was analysed using active thermography with induction excitation. The result obtained is presented in Figure 28. It clearly confirms the previous results and therefore shows the interest of this non-destructive testing method.

\subsection{Study of defects not open to the surface}

The last study we developed was aimed at approaching the possibilities of active infrared thermography as regards the detection of defects not open to the surface in metallic samples. The sample we studied is a 6 - $\mathrm{mm}$ thick steel plate which was machined to obtain 5 steps with thicknesses ranging between $2 \mathrm{~mm}$ and $6 \mathrm{~mm}$ (in steps of $1 \mathrm{~mm}$ each). The examined defects are flat-bottomed holes machined in each step. The diameters of these holes are $1.5 \mathrm{~mm}, 3 \mathrm{~mm}, 4 \mathrm{~mm}, 6 \mathrm{~mm}$ and $8 \mathrm{~mm}$ respectively. The depth at which each hole is located is equal to the thickness of the step minus $1 \mathrm{~mm}$ (Fig. 29).

We studied this stepped block by means of infrared thermography with flash lamp excitation, then by means of infrared thermography with induction excitation.

The result obtained with flash lamp excitation infrared thermography is presented in Figure 30. First, this result shows that this method actually allows defects not open to the surface to be detected, then it gives a few indications as to the limits of the method. On the one hand, it shows that this method allows detection of defects with diameters of $6 \mathrm{~mm}$ and $8 \mathrm{~mm}$ down to a depth of $5 \mathrm{~mm}$, and on the other hand it shows that the method allows detection of a defect with a diameter of $3 \mathrm{~mm}$ down to a depth of $2 \mathrm{~mm}$. And, finally, it shows that, at a depth of $1 \mathrm{~mm}$, all defects were detected.

Then we examined this stepped block using infrared thermography associated with induction excitation. The result obtained is presented in Figure 31. It first shows that this method also allows defects not open to the surface to be detected. Then it shows less diffuse defect signatures than with the flash lamp excitation method. Finally, it shows that this method allows detection of flat-bottomed holes of $4 \mathrm{~mm}, 6 \mathrm{~mm}$ and $8 \mathrm{~mm}$ down to a depth of $4 \mathrm{~mm}$, detection of holes with a diameter of $3 \mathrm{~mm}$ down to a depth of $3 \mathrm{~mm}$, and detection of holes with a diameter of $1.5 \mathrm{~mm}$ down to a depth of $2 \mathrm{~mm}$. This active infrared thermography variant then seems to be the variant which allows a wider detection of defects. It seems to show the possibility to detect a defect at a depth equal to its diameter. Therefore, this method could be used to inspect thin plates and it might become useful to detect, for instance, losses of thickness due to corrosion.

\section{Conclusion}

In this work, we tried to approach the possibilities of infrared thermography for nondestructive testing of industrial metal parts. We first tried to approach the possibilities of passive infrared thermography. Within this scope, we demonstrated that this method allowed defects visible with the naked eye to be easily detected on deepdrawn parts, in laboratory conditions and also at the end of a production line. Therefore, this method may substitute for the visual inspection and allow this inspection to be automated by providing better detection of cracks and incipient cracks than vision inspection. Then, in a second study, we approached the possibilities of active infrared thermography. For that purpose, we implemented three different excitation sources: laser excitation, flash lamp excitation and induction excitation. Within this scope, we first demonstrated that this method allows the detection of fissures in forged parts; these defects are not visible with the naked eye and can only be detected by magnetic particle testing. Then we highlighted the importance of this type of testing, as it is more environmentally friendly and much less harmful to operators' health than the NDT methods usually implemented (fluorescent penetrant testing and magnetic particle testing), which are potentially more polluting. We also demonstrated the interest of induction excitation, which allows very thin defects to be detected and gives access to very marked radiation signatures, thereby making defect detection easier. Then we showed that the active infrared thermography method also allows defects not open to the surface to be detected, and we also highlighted the interest of 


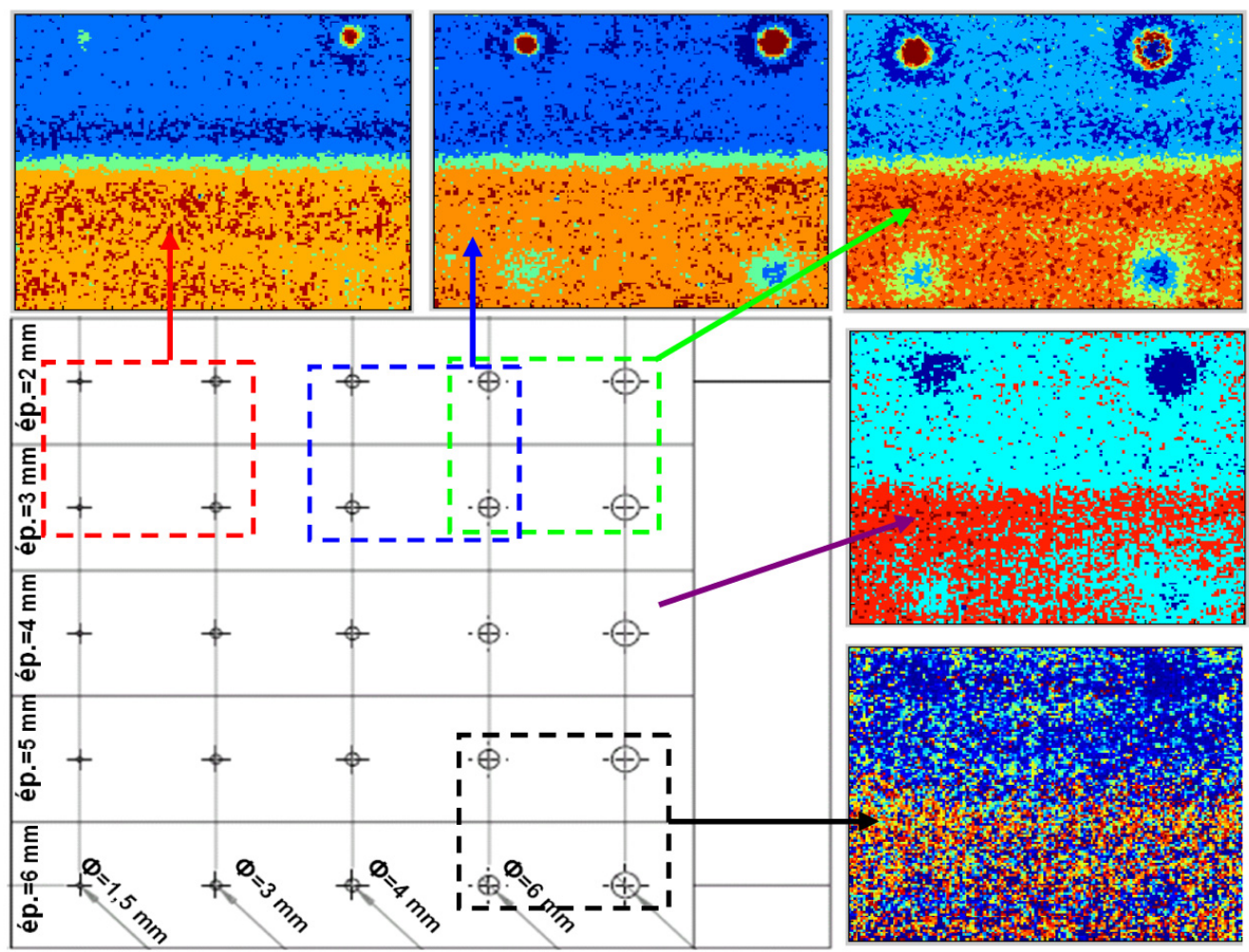

Fig. 30. Analysis of a stepped block using infrared thermography with flash lamp excitation.

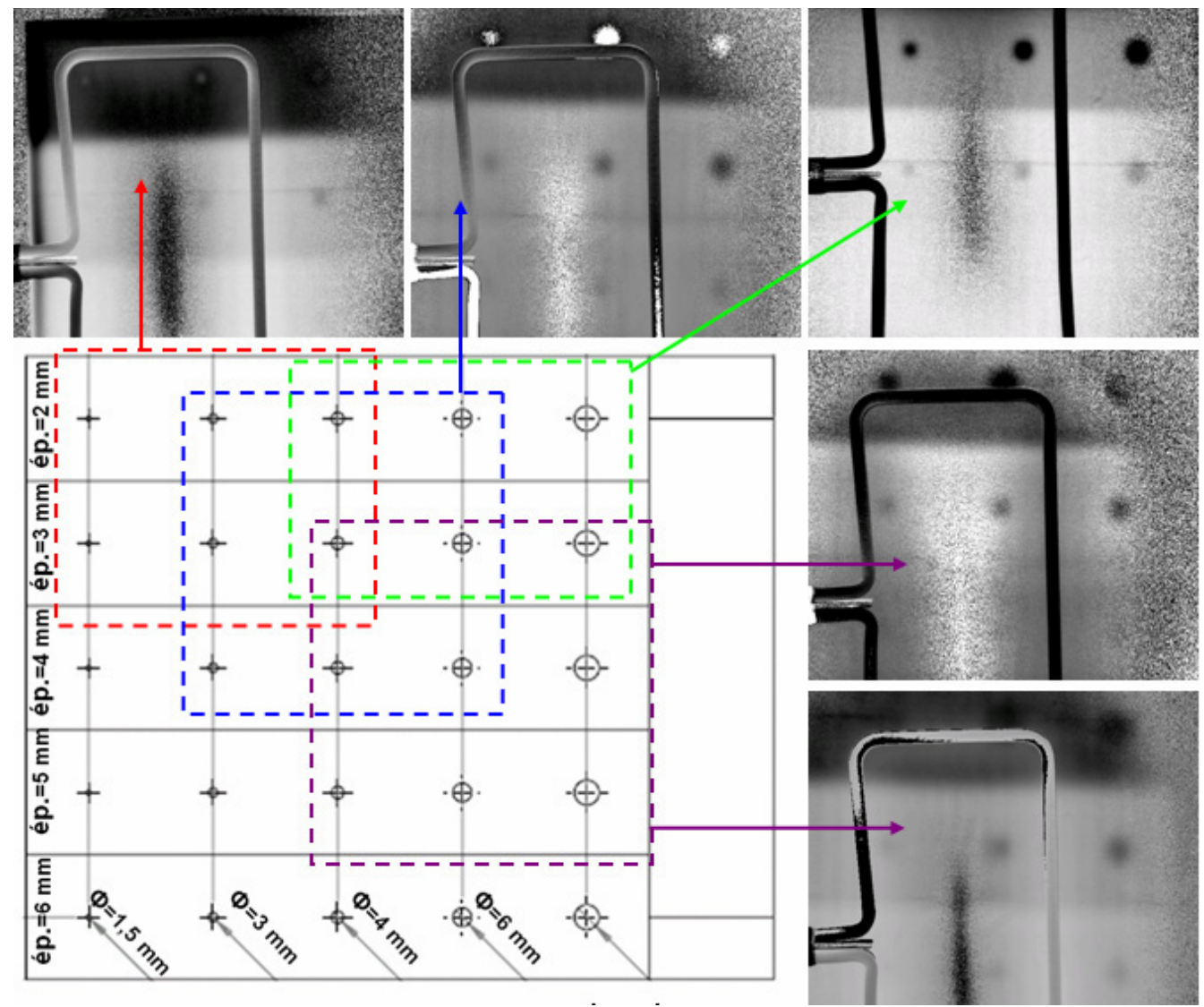

Fig. 31. Analysis of a stepped block using infrared thermography with induction excitation. 
induction excitation, which has better performance than flash lamp excitation. Finally we empirically determined that the photothermal method made it possible to detect a defect not open to the surface (corrosion type) if its depth was lower than its diameter. These results are very encouraging and need to be completed, for instance by better determining the limits of active thermography and assessing the possibility of automation of such a testing process. Studies on these subjects are in progress.

\section{References}

[1] D. Pajani, Mesure par thermographie infrarouge, Chap. 8 - Les applications de la thermographie, p. 331, 1989, ISBN: 2-9504171-0-8

[2] D. Pajani, Mesure par thermographie infrarouge, Chap. 1 - Introduction, 1989, p. 11, ISBN: 2-9504171-0-8

[3] X. Maldague, Theory and practice of infrared technology for non-destructive testing, Ed. Willey, 2001, ISBN: 0471-18190-0

[4] J.L. Bodnar, M. Edée, Wear characterization by photothermal radiometry, Wear 196 (1996) 54-59

[5] J.L. Bodnar, M. Edée, C. Menu, R. Besnard, A. Le Blanc, M. Pigeon, J.Y. Sellier, Cracks detection by a moving photothermal probe, J. Phys. IV 4 (1994) C7-592

[6] H.G. Walther, D. Fournier, J.C. Krapez, M. Luukkala, B. Schmitz, C. Sibilia, H. Stamm, J. Thoen, Photothermal Steel Hardness Measurements - Results and Perspectives, Anal. Sci. 17 (2001) s158-s160

[7] Th. Zweschper, A. Dillenz, G. Riegert, D. Scherling, G. Busse, Ultrasound excited thermography using frequency modulated elastic waves, Insight 45 (2003) 178-182

[8] J. Vrana, M. Goldammer, J. Baumann, M. Rothenfusser, W. Arnold, Mechanisms and Models for Crack Detection with Induction Thermography, Rev. Prog. QNDE 27 (2008) 475-482

[9] H. Mooshofer, M. Goldammer, W. Heine, M. Rothenfusser, J. Bass, E. Lombardo, J. Vrana, Induktionsthermographie zur automatischen Prüfung von Generatorkomponenten, DGZfP-Jahrestagung 2009, Münster, Allemagne, 2009
[10] J. Bamberg, G. Erbeck, G. Zenzinger, EddyTherm: Ein Verfahren zur bildgebenden Rißprüfung metallischer Bauteile, ZfP-Zeitung 68 (1999) 60-62

[11] G. Riegert, Th. Zweschper, A. Dillenz, G. Busse, Wirbelstromangeregte Lockin-Thermografie - Prinzip und Anwendungen, DACH - Jahrestagung 2004 Salzburg, http://www.ndt.net/article/dgzfp04/ papers/v90/v90.htm

[12] J.L. Bodnar, K. Mouhoubi, G. Szatanik-Perrier, J.M. Vallet, V. Detalle, Photothermal thermography applied to the non-destructive testing of different types of works of art, IJOT, DOI:10.1007/s10765-012-1301-2

[13] J.L. Bodnar, Contrôle optique des matériaux par radiométrie photothermique aléatoire infrarouge, Revue de l'électricité et de l'électronique 2 (2007) 68-74

[14] X. Maldague, Introduction to NDT by active infrared thermography, Mater. Evaluation 6 (2002) 1060-1073

[15] S. Maillard, J. Cadith, Walaszek H., Bodnar J.L., La thermographie infrarouge active et ses nouvelles applications aux matériaux métalliques, COFREND congress proceedings, Dunkerque, France, 2011

[16] S. Maillard, J. Cadith, G. Legros, P. Bouteille, H. Walaszek, J.L. Bodnar, Contrôle de matériaux métalliques par thermographie active, Thermogram congress proceedings, Chalons en Champagne France, 2011

[17] S. Maillard, J. Cadith, D. Eschimese, H. Walaszek, H. Mooshofer, J.C. Candore, J.L. Bodnar, Towards the use of passive and active infrared thermography to inspect metallic components in the mechanical industry, QIRT congress proceedings, Laval, Quebec, 2010

[18] S. Maillard, J. Cadith, H. Walaszek, J.L. Bodnar, Contrôle non destructif de matériaux métalliques par thermographie infrarouge active, Mesures et Techniques Optiques pour l'Industrie, Lille France, 2011

[19] P. Bouteille, G. Legros, S. Maillard, J. Cadith, J.L. Bodnar, Induction active thermography as an alternative to magnetic particle inspection, QIRT congress proceeding, Naples, Italie, 2012

[20] S. Maillard, J. Cadith, P. Bouteille, G. Legros, J.L. Bodnar, V. Detalle, Non-destructive testing of forged metallic materials by active infrared thermography, IJOT, DOI : 10.1007/s10765-012-1275-0 